\title{
La crítica de Bergson a la idea de mundo
}

\author{
The Bergson's Critic to the Idea of the World \\ ROBERTO ALONSO HERNÁNDEZ \\ BENEMÉRITA UNIVERSIDAD AUTÓNOMA DE PUEBLA
}

Recibido: 13/03/2019 Aceptado:05/04/2019

\section{RESUMEN}

Este texto muestra que para Bergson la intuición de la duración es una alternativa a la visión cuantificadora de la inteligencia acerca de la temporalidad. En este sentido la filosofía y la termodinámica se relacionan, ya que las dos piensan que existe una reinterpretación de la temporalidad que tiene como características la creatividad y la irreversibilidad; esta reinterpretación ayuda a romper con la representación del mundo creada por el sentido común y el internet, en la que el orbe puede ser deducido a partir de del establecimiento de un conjunto de leyes que determinan el comportamiento de sus elementos.

\section{PALABRAS CLAVE}

BERGSON, DURACIÓN, MUNDO, INTELIGENCÍA, COMPLEJIDAD.

\section{ABSTRACT}

This paper aims to show that Bergson thinks duration it's an alternative to the quantifying vision of intelligence about time. In that sense, philosophy and thermodynamics relate, because the two of them think there is a reinterpretation of time which has as characteristics creativity and irreversibility; this new way of understanding time helps us to break with the image of the world created by the common sense and the internet, in which the globe can be deducted by the establishment of a set of laws that determine the behavior of all it's elements.

KEYWORDS

BERGSON, DURATION, WORLD, INTELLIGENCE, COMPLEXITY 


\section{I.INTRODUCCIÓN}

ESTE TRABAJO TIENE COMO COMETIDO pensar junto a Bergson el problema de la imagen cotidiana del mundo, hemos escogido este tema porque creemos que el pensamiento de nuestro autor puede ayudarnos a entender que en la cotidianidad el uso de la inteligencia provoca que el ser humano tenga una representación del mundo, en la que el conjunto de sus elementos son calculados, o por lo menos pueden ser calculables a través de una lógica causal y dicotómica, en la que el todo es una imagen ya configurada. Por ese motivo pensamos que el acercamiento que la propuesta bergsoniana tiene con la termodinámica permite romper con esta imagen simple que se basa en la separación sujeto-objeto, debido a que esta teoría científica muestra la eficacia que tiene el tiempo en el mundo material y en los vivientes. La introducción del tiempo efectivo que se encuentra en la obra de Bergson y en la termodinámica del siglo XIX y XX muestra que los procesos por los cuales el mundo pasa, van más allá de una representación que se origina en el establecimiento de categorías y leyes que describen el comportamiento de objetos.

Para poder cumplir con nuestro objetivo, este trabajo está estructurado de la siguiente forma: comenzamos por una presentación de la propuesta metafísica de Bergson en Introducción a la metafísica y La evolución creadora. Nosotros hemos escogido estas dos obras porque parten de la idea de que la duración en general es un despliegue creativo, en el que los diversos seres particulares se encuentran en un proceso de constante evolución creadora que no permite delimitar su esencia a partir de conceptos fijos.

El segundo apartado de nuestro trabajo es un estudio sobre la obra Materia y memoria en el que buscamos demostrar que, para nuestro filósofo la inteligencia da origen a una postura en la que los objetos materiales, los seres vivos y el hombre mismo pueden ser determinados a cada instante mediante el cálculo; a pesar de esto, en esta obra se defiende que la acción de los seres vivos es un centro de indeterminación que se diferencia de la regularidad de la interacción material, y que ejemplifica la influencia que el ser humano tiene en las situaciones en las que se encuentra. Esto rompe con la idea de que el hombre puede sustraerse de las relaciones efectivas que acontecen en el mundo, y al mismo tiempo, nos permite entender el nivel de compenetración que existe entre las cosas y los seres humanos.

La tercera parte de nuestro trabajo es un estudio de la relación que Bergson establece en La evolución creadora entre su postura y el segundo principio de la termodinámica; en esta obra encontramos que para el filósofo francés el segundo principio de la termodinámica logró mostrar que el tiempo en los sistemas físicos es eficaz, es decir, las relaciones de los elementos materiales que lo conforman no pueden volver a un estado anterior. En este sentido 
podemos observar que el puente establecido por la propuesta bergsoniana entre la filosofía y la termodinámica influenció de forma directa los estudios hechos por Ilya Prigogine sobre las estructuras disipativas fuera del equilibrio; esta postura científica demuestra que no todos los fenómenos que acontecen en el mundo pueden ser explicados mediante un sistema inteligente de pensamiento, en el que se presuponen las interacciones de los elementos de un sistema.

La última parte de este escrito trata de dilucidar el problema que se suscita cuando la consciencia tiene acceso a un medio de interacción masiva como lo es el internet, en este sentido pensamos que lo expresado en Materia y memoria y La evolución creadora nos ayuda a entender que las noticias presentadas en internet se convierten en temas masivos, porque apelan a la función inteligente de tratar al tiempo y al espacio como un conjunto de objetos que pueden ser artificialmente reconstruidos; así el tiempo real en el que se transmite una noticia da cuenta de una temporalidad cuantitativa y no cualitativa. Este tipo de interacciones entre las personas y el internet crean la ilusión de que podemos tener un acceso total a los fenómenos, al pretender que la suma de puntos de vista es igual que una visión global de los acontecimientos; sin embargo, todas estas vistas externas no pueden llegar a un conocimiento que agote el suceso del que se habla.

Las cuatro partes de este trabajo nos permiten concluir que a diferencia del pensamiento cotidiano, la filosofía de Bergson y la termodinámica del siglo $\mathrm{XX}$ nos muestran que el mundo no puede ser un contenido del entendimiento, porque los diferentes procesos en los que se encuentran los elementos que constituyen al mundo no son representables mediante un entramado de categorías y conceptos de los que la inteligencia dispone para hacer un calculo del estado del mundo, el cual es entendido como una cosa que está separada del sujeto que la conoce. Es por este motivo que el mundo no se reduce a una regularidad ficticia que parte de la idea de que lo mismo engendra lo mismo.

\section{II.UNA SALIDA DE LA REPRESENTACIÓN FUNCIONAL DEL TIEMPO}

En Ensayo sobre los datos inmediatos de la conciencia Henri Bergson mostró que uno de los retos más importantes a los que se enfrentaban la filosofía y la física modernas era que dependían de un método externo para poder conformar sus objetos de conocimiento. Pero el origen de este problema se encontraba en que, de forma cotidiana, el ser humano al conocer pone en marcha un método de conocimiento que busca fijar el movimiento de los objetos para después tomar vistas de ellos a partir de diferentes perspectivas. Este método es muy útil cuando queremos medir la acción que tienen diversos objetos exteriores entre sí y también con nosotros. Un ejemplo del uso de este método son los esquemas que ilustran el crecimiento de una planta, en ellos existen un conjunto de ilustraciones que nos muestran las diferentes partes 
de su desarrollo; pero estas descripciones no pueden expresar las complejas relaciones temporales que hacen que cada proceso de desarrollo dé como resultado una planta única. Lo que le falta a este método de conocimiento es darse cuenta de que el ser de los diversos entes no se agota en el sentido práctico de las cosas. En su libro La formación del espiritu científico Gaston Bachelard cita un pasaje de El pensamiento y lo moviente en el que se hace énfasis en que el ser humano tiende a darle mayor importancia a las ideas útiles, porque están insertas en un movimiento de esquematización de lo real basado en un conjunto de hábitos intelectuales:

Costumbres intelectuales que fueron útiles y sanas pueden, a la larga, trabar la investigación. 'Nuestro espíritu -dice justamente Bergson- tiene una tendencia irresistible a considerar más claras las ideas que le son útiles más frecuentemente."'La idea conquista así una claridad intrínseca abusiva (Bachelard, 2011 [1948]: 16-17).

Como podemos observar Bachelard piensa que uno de los elementos que es necesario poner de relieve en la propuesta bergsoniana, es la crítica al modo en el que la inteligencia del ser humano trata de fijar mediante sistemas conceptuales el movimiento cambiante de la realidad. Un ejemplo de este proceso es el que se tematiza en Introducción a la metafísica, obra en la que Bergson estudia la problemática que se estaba desarrollando en el ámbito filosófico de su tiempo, debido a que la tendencia era analizar la realidad mediante conceptos, y a través de ellos tomar partido por escuelas de pensamiento. Al contrario de esta forma de proceder, nuestro autor proponía que el paso más importante a seguir era identificar la intuición que dio origen a una postura filosófica, porque al hacerlo podemos llegar a un conocimiento del ser de los entes que no está mediado por un conjunto sistemático de conceptos. Esta forma de entender el filosofar por parte de nuestro autor se expresa de la siguiente manera:

Por último, la filosofía así definida no consiste en elegir entre conceptos y en tomar partido por una escuela, sino en buscar una intuición única de donde descender con igual facilidad a los diversos conceptos, ya que nos hallaremos por sobre las divisiones de escuelas (Bergson, 1973 [1903]: 44).

En este punto es muy importante hacer notar que este establecimiento de un conjunto de conceptos que permiten conocer a un objeto también hace que el sujeto de conocimiento le dé un tratamiento espacial al tiempo, porque en esta forma de acercarse al objeto no se tiene en cuenta que, cuando el sujeto fija a un objeto para conocerlo mejor lo determina temporalmente; ya que el objeto no está siendo pensado inserto dentro del continuo temporal del que es integrante. Esto demuestra que lo único importante para esta forma de acceder 
al conocimiento es el establecimiento de un conjunto de símbolos generales que puedan darle una estructura deductiva a la realidad; en este sentido Le Roy muestra que para Bergson el conocimiento de la inteligencia tiene validez porque se originó en un primer momento en lo real, pero su desventaja es que solamente puede hacer un análisis de ese acceso a través de conceptos y categorías ya establecidas que tienen un sentido práctico, por eso no puede dar cuenta de la complejidad de lo real: «La inteligencia, pues, nos hace conocer, si no lo real, por lo menos algo real, a saber, aquello por lo cual la realidad es objeto posible de acción industrial o discursiva» (Le Roy, 1932 [1928]: 187).

¿Qué es esa complejidad que divide lo real de la realidad? Para comenzar diremos que en Ensayo sobre los datos inmediatos de la conciencia hay una crítica del concepto de intuición esgrimido por Kant en la Crítica de la razón pura, en este estudio de la obra kantiana podemos ver que el interés principal de Bergson es mostrar que la división entre el sujeto de conocimiento y el objeto conocido es una forma de acceso a las cosas que privilegia a la mediación como punto de partida del conocer. Esto significa que todo ser humano al querer establecer una relación de conocimiento tiene que apelar a la razón y sus categorías para acceder a las cosas exteriores; en este sentido vemos que la propuesta bergsoniana identifica que esta separación se fundamenta en una postura sobre el tiempo, que lo utiliza como el medio que permite entender al cambio sin caer en la contradicción. Para ahondar un poco más en este tema es necesario remitirnos al concepto de tiempo expuesto en la Estética trascendental, que es caracterizado de la siguiente forma:

Aquí añadiré que el concepto de cambio, y con él el de movimiento (como cambio de lugar), sólo es posible en la representación del tiempo y a través de ella; igualmente, que si esta representación no fuese intuición (interna) a priori, no habría concepto alguno, fuese el que fuese, que hiciera comprensible la posibilidad de un cambio, es decir, de una conexión de predicados contradictoriamente opuestos en una misma cosa [...] (Kant, 2014 [2010]: 71)

Si seguimos la propuesta kantiana, el tiempo sería una de las condiciones de aparición de las cosas y por ese motivo se encuentra en el sujeto y no en el objeto, lo cual quiere decir que, el entendimiento ordena los datos de la sensibilidad mediante esta forma pura de la intuición sensible. En este punto tenemos que hacer énfasis en que para nuestro autor el concepto de intuición de la Crítica de la razón pura es entendido como la mediación por la cual las cosas exteriores se dan a nuestro psiquismo; esto nos lleva a ver que la separación kantiana entre la cosa en sí y el ser humano hace que el entendimiento sea el único que puede establecer una relación entre estos dos términos, y para poder hacer esto tiene un conjunto de condiciones: «Pero, en definitiva, todo pensar tiene que hacer referencia, directa o indirectamente 
[mediante ciertas características], a intuiciones y, por consiguiente (entre los humanos), a la sensibilidad, ya que ningún objeto se nos puede dar de otra forma» (Kant, 2014 [2010]: 61).

Como sabemos, en esta obra del filósofo de Königsberg la idea de mundo es una antinomia de la razón, porque el mundo sensible no puede ser intuido en una sola representación acabada que sintetice la totalidad de los fenómenos, por ese motivo esta idea era algo a lo que el entendimiento no podía acceder. A pesar de esto Bergson se da cuenta de que la inteligencia como facultad del ser humano se empecina en salir de los limites propios del ámbito en el que se origina (la acción), y busca hacer un cálculo de todas las interacciones de los elementos materiales que constituyen una situación. Pero este proceso de la conciencia no se limita a la situación presente, la inteligencia tiene en sí misma la inclinación natural de expandir su influencia a todos los objetos y sus interacciones actuales o posibles. Yankélévitch en su libro a cerca del pensamiento de Bergson hace énfasis en está parte sobre la crítica a la inteligencia, que como proceso, sale de sí misma para ver como objeto de su acción a las cosas exteriores: «La inteligencia, por lo contrario, capaz de fabricar 'herramientas para hacer herramientas', posee por naturaleza una capacidad de desdoblamiento infinito, que le permite reflexionar sobre sí, y encuentra en el lenguaje un medio de separar definitivamente a la inteligencia de sus objetos» (Yankélévitch, 2006 [1962]: 234).

En este punto podemos ver que Bergson en su obra de 1907 La evolución creadora vuelve a retomar su crítica a la filosofía de Kant, pero dando un paso muy importante porque distingue dos formas de entender la intuición (algo que en Ensayo sobre los datos inmediatos de la conciencia no pudo hacer, debido a que en esta obra de 1889 no había conceptualizado la diferencia entre la inteligencia y la intuición como dos accesos al ser de las cosas). La primera está determinada por una filiación a la inteligencia que distingue entre el sujeto que conoce y el objeto exterior que es conocido. Como lo vimos antes, esta diferencia solamente se puede hacer si se paga el precio de la utilización de un tiempo abstracto que se comporta como espacio y permite entender el movimiento como sucesión de instantes; esta ventaja práctica hace que un objeto exterior pueda ser conocido con la ayuda de categorías y conceptos preconcebidos. Ante esto el filósofo francés piensa que es necesario que la filosofía acceda a otro modo de conocimiento, por ese motivo la intuición de la duración es propuesta como el medio que permite introducirse de forma inmediata en la temporalidad de los entes; en este sentido en La evolución creadora se expresa que estas dos formas de entender la intuición no son 
puntos de vista auto excluyentes, sino más bien dos accesos al ser que se originan en niveles de comprensión diferentes:

Pero Kant no quería ni podía admitir esta dualidad de intuición. Para admitirla, hubiera tenido que ver en la duración el tejido mismo de la realidad, y por consiguiente distinguir entre la duración sustancial de las cosas y el tiempo dispersado en el espacio (Bergson, 2012 [2007]: 358).

A diferencia del concepto de intuición del filósofo de Königsberg, el pensamiento de Bergson muestra que la intuición metafísica reconoce que los distintos entes no pueden concebirse como un conjunto de objetos estático, ellos solamente tienen esta característica cuando la inteligencia los analiza gracias a una reducción del tiempo cualitativo en cuantitativo que tiene como elemento principal ser infinitamente divisible. En el texto de 1903 Introducción a la metafisica, la propuesta bergsoniana muestra que la intuición metafísica al tomar en cuenta al tiempo como duración permite entender de una nueva forma al ser; para Bergson las cosas nunca están ya hechas, ellas siempre se están haciendo, y los estados en los que la inteligencia las constituye no son estables debido a que pasan por alto al tiempo efectivo; a diferencia de este tratamiento, la filosofía que tiene en vista al ser de las cosas, entendido como duración, remarca que las cosas exteriores al igual que nuestra conciencia siempre se encuentran durando:

No existen cosas hechas, sino sólo cosas que se hacen; ni estados que se mantienen, sino estados que cambian [...] La conciencia que tenemos de nuestra propia persona, en su continua fluencia, nos introduce en el interior de una realidad sobre cuyo modelo debemos representarnos las demás (Bergson, 1973 [1903]: 68).

Esta nueva forma de entender el ser de las cosas permite romper con la imagen del mundo que crea el sentido común cuando pone en marcha el método de la inteligencia, el cual establece relaciones cuantitativas entre objetos exteriores que se encuentran bien delimitados unos con otros; en este sentido cabe recalcar que las relaciones que estos objetos pueden establecer son solamente relaciones materiales.

\section{III.LA IMPORTANCIA DE UNA REINTERPRETACIÓN DEL ACTO EN LA OBRA MATERIA Y MEMORIA}

Nosotros creemos que una lectura heterodoxa de Materia y memoria permite comprender que, el capítulo I de esta obra abre la posibilidad de una reinterpretación del acto gracias a la primera tesis que propone: «Heme aquí, pues, en presencia de imágenes [...] percibidas cuando abro mis sentidos, 
inadvertidas cuando los cierro. Todas esas imágenes obran y reaccionan unas sobre otras en todas sus partes elementales según leyes constantes [...]» (Bergson, 2007 [2006]: 33). En esta parte podemos ver que una visión mecánica del universo buscaría establecer un conjunto de leyes con las cuales poder predecir el movimiento de los elementos materiales del mundo y del espacio; esta forma de entender las interacciones de los cuerpos materiales se basa en la idea de que el ser humano puede salir del conjunto de esas relaciones. Esta postura tiene dos ventajas: la primera es que el hombre puede sacar un conocimiento útil del conjunto de las interacciones al aislar las situaciones y deducir de ellas leyes, las cuales permiten determinar el comportamiento de los objetos materiales en situaciones similares; la segunda ventaja es que el ser humano encubre su acción en el mundo material porque pareciera ser que la acción que se inaugura con este punto de partida teórico es desinteresada, pero en realidad ella sigue teniendo influencia en el mundo material. En este punto podemos ver que el sentido común al configurar su representación del mundo da por sentado que la acción humana no afecta cualitativamente el ser de los entes con los que se relaciona, por ese motivo Bergson piensa que es necesario mostrar que los seres vivos (y en particular el ser humano) ejercen una influencia importante en el desarrollo de las relaciones materiales. En Materia y memoria los vivientes son vistos como centros de indeterminación, ya que ellos logran romper con el ritmo regular con el que la materia se comporta. Esto es expresado por el filósofo francés de la siguiente forma:

Ahora bien, si los seres vivientes constituyen en el universo 'centros de indeterminación', y si el grado de esta indeterminación se mide a través del número y la elevación de sus funciones, se concibe que su sola presencia pueda equivaler a la supresión de todas las partes de los objetos en las que sus funciones no están comprometidas (Bergson, 2007 [2006]: 50-51).

En este punto podemos observar que la vida en general y el ser humano en particular tienen como característica romper con la regularidad del movimiento material. Esta nueva forma de relacionarse con las cosas hace que los seres vivientes creen a cada instante nuevas acciones que influyen en las cosas exteriores y los seres vivos que conforman su situación. Otro aspecto que es necesario resaltar de la cita anterior es que pone de manifiesto que los seres vivos se relacionan con sus circunstancias a partir del interés que tienen en las cosas que los rodean, ese interés es el que hace que un objeto pueda ser percibido por la conciencia. Lo que este proceso demuestra es que el ser humano no puede separar totalmente la actividad intelectual de la vida práctica; todas las cosas con las que las personas se relacionan provocan un cierto interés en ellos. 


\section{IV.BERGSON Y LA TERMODINÁMICA}

Materia y memoria significó un paso grande en la propuesta bergsoniana al establecer que la conciencia nunca se encuentra de forma pura en el mundo material, otro aspecto importante es que ella mostró que el ser humano a través de su acción es causa de indeterminación en el conjunto material del universo; pero no es hasta La evolución creadora que la relación entre el ser humano y su entorno se hace clara en el momento en el que Bergson expresa que tanto la vida como la materia tienen duración, por lo que las dos se influencian recíprocamente. La unión entre la vida y la materia hace posible entender que en el universo conocido la vida no puede estar separada de la materia; esta aclaración permite volver a unir la relación que el sentido común había roto, debido a que la puesta en marcha del método de la inteligencia por parte de la conciencia provocaba que lo real se dividiera en objeto y sujeto de conocimiento. En este sentido Chevalier demuestra que en La evolución creadora hay un cambio en la forma en la que el pensamiento de Bergson entendía la materia, gracias a una reinterpretación de la inteligencia y del espacio simbólico:

El espacio no es ya una propiedad de las cosas una especie de materia o de trama en la que se recortarían las distintas magnitudes; es tan solo el esquema de la divisibilidad infinita que tendemos, por decirlo así, por debajo de la materia para recortarla en objetos independientes que ofrecen una presa a nuestra acción. La materia no es extensa; se extiende (Chevalier, 1968 [1966]: 525).

En su Historia del pensamiento Chevalier pone de manifiesto que después de Materia y memoria, la materia es entendida como un tipo de movimiento que la inteligencia inmoviliza a través de la idea de un espacio infinito, que se pone por debajo de ella y permite que se establezca una imagen analizable a través de formas que son exteriores entre sí. Nosotros creemos que uno de los elementos que hicieron posible esta separación entre la materia y el espacio es la revisión que nuestro autor hace de la termodinámica de su tiempo; ya que en esta postura científica existe la intuición de que la interacción de todos los elementos de un sistema no puede ser entendida de forma mecánica, es decir, las interacciones de los elementos materiales que existen en un sistema no solamente son entendidas a través de la idea de un tiempo espacializado que permite la sucesión. La importancia que tiene el segundo principio de la termodinámica para La evolución creadora ejemplifica que la ciencia del siglo XIX pudo ir más allá del uso de la inteligencia, para llegar a la intuición de 
que en el universo se dan un conjunto de fenómenos en los que el tiempo es visto como cambio cualitativo y no cuantitativo:

Sucede de otro modo con el segundo principio de la termodinámica. La ley de degradación de la energía, en efecto, no se apoya esencialmente sobre magnitudes [...] seguiría siendo vagamente formulable y habría podido ser formulada rigurosamente en líneas generales, aún cuando no se hubiera pensado nunca en medir las diversas energías del mundo físico [...] (Bergson, 2012 [2007]: 249250)

La ley de la degradación de la energía es para Bergson el medio de comunicación entre la filosofía y la ciencia porque demuestra que existe una intuición que guía a estos dos modos de conocimiento y les permite tener un acceso a lo real; gracias a este punto de partida la termodinámica puede entender que el conjunto de interacciones entre los distintos elementos de un sistema está vinculado con el tiempo efectivo, el cual hace que todas las relaciones del sistema tengan la característica de una acción reciproca que modifica constantemente a cada una de sus partes.

Uno de los científicos del siglo XX que se adscribe al estudio de la termodinámica y que se dio cuenta de la valía del pensamiento del filósofo francés fue Ilya Prigonine, que en su obra Entre el tiempo y la eternidad hace una recuperación del concepto de duración de Bergson. Esto obedeció a que el científico belga pensaba que la ciencia de su tiempo estaba pasando por una transformación en la que los principios de la física clásica estaban siendo reformulados; una de las bases de este cambio es que la ciencia del siglo XX comienza apartarse de la idea de tiempo de la mecánica, la cual en últimas cuentas llegaba a postular que el tiempo ya estaba dado, porque a partir de las interacciones materiales de los elementos del universo se podía deducir su comportamiento pasado, presente y futuro. En este sentido vemos que para Prigogine es necesario retomar de forma científica la reinterpretación del tiempo que estableció el filósofo francés.

Nuestra andadura [...] En cierto sentido es paralela a la de Bergson, para quien el punto de partida de todo pensamiento en busca de la realidad debía ser[...] el 'sentimiento que tenemos de nuestra evolución y de la evolución de todas las cosas en la duración pura'. No obstante, nuestro punto de partida [...] será [...] una evidencia inmanente a la propia física [...] (Prigogine, 1994 [1988]: 13)

El estudio hecho por el científico belga sobre las estructuras disipativas alejadas del equilibrio tiene como idea principal una nueva forma de entender al tiempo que se caracteriza por la irreversibilidad; esta propiedad hace que una estructura que dura desarrolle dos tipos de comportamientos: el primero 
es un arreglo en el que los elementos que constituyen este sistema agotan las posibilidades de acción reciproca y llegan a un equilibrio en el que la energía se acaba; el segundo es la posibilidad de que un sistema a través del tiempo logre complejizar en cada momento de su desarrollo las relaciones que lo conforman, dando como resultado una estructura compleja que dura y que en cada etapa tiene diferentes cualidades. Esta reinterpretación de la temporalidad es llevada por Prigogine al campo de la cosmología, en el que demuestra la existencia de una explicación del cosmos en la que el tiempo tiene como atributos la creatividad y la imprevisibilidad; estas dos características son tematizadas en su texto Naturaleza y creatividad, obra en la que se vuelve a hablar del pensamiento de Bergson. En este punto podemos ver que para el científico belga la creatividad que se encuentra en el universo y la imprevisibilidad de las estructuras que resultan de ese proceso, no pueden ser determinadas bajo una sistematización científica que tenga el afán de hacer una descripción total del comportamiento de los objetos materiales:

Por lo tanto, podemos decir que la crítica de Bergson es totalmente pertinente. Cuando dice que en física lo cualitativamente nuevo, la innovación, no tienen lugar, expresa una de las consecuencias esenciales del tipo de postulado que instauraron los fundadores de la ciencia moderna para lograr su ambición: matematizar la naturaleza [...] (Prigogine y Stengers, 2009 [1983]: 77)

Otros pensadores que reconocen la importancia de la filosofía de Henri Bergson en torno al dialogo con la termodinámica y la revaloración de la importancia del tiempo cualitativo son Eric Schneider y Dorion Sagan, los cuales en su texto La termodinámica de la vida reconocen que el filósofo francés desarrolló la intuición de que el universo estaba conformado mediante un proceso creativo en el que la energía se modifica de forma física y química. Pero lo más importante es que la perspectiva bergsoniana remarca que la termodinámica no se restringe a una postura científica en la que el mundo es solamente entendido como la interacción de objetos materiales; la vida también está ligada a los procesos de transformación de la energía, ya que en los seres vivos hay un conjunto de relaciones entre los elementos que los constituyen, en las que la captación y el retardo de la disipación de la energía son sus cualidades principales:

No podemos comulgar con la tesis de Bergson de que hay implicadas 'propiedades vitales' más allá de la física y la química, pero reconocemos que enfatizó correctamente el papel de la utilización de la energía y la demora de su disipación en los sistemas vivos. La termodinámica del no equilibrio deja claro que lo vivo es un proceso químico y físico dentro de un universo energético (Schneider y Sagan, 2009 [2008]: 189). 


\section{V.EL INTERNET Y EL PROBLEMA DE LA CONCIENCIA}

En este apartado abordamos el problema que se suscita cuando el internet como medio de interacción masiva pone frente a un conjunto de personas, un sin número de noticias que se relacionan con un acontecimiento, pero que lo presentan desde diferentes perspectivas. Arnaud Spire hace la siguiente reflexión sobre la forma en la que la velocidad de la comunicación afecta de forma negativa el proceso de desarrollo de las interacciones sociales:

En todo caso, Prigogine y Stengers han demostrado lucidez al preguntarse en qué se transformaría el 'sistema democrático' en el seno de una sociedad cuyos medios de comunicación permitirían una consulta permanente de cada cual por un organismo representativo central, permitiendo así que la velocidad de comunicación dominara totalmente la velocidad de las interacciones no lineales locales entre individuos (Spire, 2000 [1999]: 19).

En base al pasaje anterior nosotros pensamos que el internet es un medio de interacción masiva porque su función principal es la de influenciar a los individuos que acceden a él, a través del dominio de un ritmo de información que afecta directamente la interacción de los seres humanos en su medio próximo, pero además en el virtual. En este sentido lo que hay que preguntarnos es: ¿el internet es la expresión de la temporalidad bergsoniana o solamente es el resultado del uso de la inteligencia y sus medios técnicos? Para poder responder a esta pregunta es necesario que hablemos del trabajo que hizo Gilles Deleuze sobre la relación que existe entre la filosofía bergsoniana y el cine, en él podemos encontrar que el filósofo de la duración tiene tres tesis sobre el movimiento, de las cuales la tercera es la más importante porque demuestra la existencia de las imágenes-movimiento en el cine. Para Deleuze la tercera tesis sobre el movimiento esgrimida en La evolución creadora puede ser expresada en la siguiente formula:

[...] además de que el instante es un corte inmóvil del movimiento, el movimiento es un corte móvil de la duración, es decir, del Todo o de un todo. Lo cual implica que el movimiento expresa algo más profundo: el cambio en la duración o en el todo (Deleuze, 2010 [1984]: 22).

Como podemos ver la diferencia que existe entre el cine y las imágenes chinescas que necesitan un movimiento externo que las superponga y les done fluidez, es que las imágenes-movimiento que componen una película dan cuenta del cambio cualitativo que se establece cuando los elementos de un encuadre interactúan entre sí, por ese motivo, aunque una película pueda ser dividida en fotogramas, esas imágenes no son posturas estables que pueden ser fijadas de forma total. Un ejemplo de esto es el cine, en él la acción de un 
protagonista no se fundamenta solamente en una individualidad que ejerce una influencia en un elemento del encuadre, la acción se crea a través de la interacción que tiene un personaje en todo su entorno. En este ejemplo podemos ver que la imagen-movimiento expresa la duración en tres niveles; en el texto La imagen-movimiento. Deleuze y la relación Beckett-Bergson Jorge Martin retoma la explicación de los tres niveles condensándola de la siguiente forma:

Desde la lectura deleuziana, a cada uno de estos niveles corresponde una realidad cinematográfica. El cuadro es la determinación de un sistema provisionalmente cerrado, el plano o imagen-movimiento es la determinación del movimiento que se establece en el sistema cerrado y el montaje es la determinación del todo. De este modo, el plano es el intermediario entre el encuadre del conjunto y el montaje del todo (Martin, 2010: 56-57).

A partir de esta descripción nosotros nos avocaremos a los dos primero niveles, en el primer nivel se puede ver que el instante permite identificar conjuntos que son dados a cerrarse artificialmente, pero que expresan la existencia del todo más allá del conjunto (un cuarto da cuenta de la existencia de una casa que está circunscrita en una una calle, la calle en una cuadra, la cuadra en una colonia... etc.) El segundo nivel expresa el advenimiento de lo nuevo a través de la influencia reciproca entre formas cerradas identificables y un entorno abierto que permite la traslación de sus elementos, pero también el cambio del entorno y los personajes. La teoría sobre el cine hecha por Deleuze nos permite mostrar la diferencia que existe entre un medio técnico cuya composición sobrepasa el uso de la inteligencia permitiéndole acceder al nivel ontológico de lo real, y el internet, un instrumento que en un primer momento fue utilizado para el intercambio de información, pero que ahora es utilizado para incidir de forma constante en la interacción de los individuos que son atravesados por él. Un filósofo que mostró la forma en la que la sociedad es moldeada por el uso del internet es Zygmunt Bauman, el cual en su obra Tiempos líquidos logra describir los proceso por los cuales ciertos actores sociales ya no están delimitados por su interacción local, sino que sus intereses, influencias e interacciones se decantan por lo virtual. Dice Bauman:

Así pues, por regla general, las elites urbanas de nuestros días no están interesadas en los asuntos de 'su' ciudad, que no es sino una localidad entre muchas, un punto minúsculo e insignificante desde la perspectiva superior del ciberespacio que, por muy virtual que sea, es su verdadera casa (Bauman, 2008 [2007]: 108).

Este pasaje nos revela el nuevo uso que el internet adquiriere, ahora el objetivo de los usuarios no es compartir y acumular información, sino 
interactuar entre sí mediante la inmediatez del traslado de datos. Es aquí donde tenemos que hacer énfasis en dos temas: el primero es que esta inmediatez no puede ser entendida como la duración de la que Bergson habla en Materia y memoria y La evolución creadora, debido a que la interacción de individuos a través del ciberespacio no se basa en la intuición de la temporalidad del otro, o de empatía con una situación; los temas que se han vuelto relevantes en internet muchas veces adquieren notoriedad, a partir de una cadena de causas ligadas por un constante bombardeo de avisos y notificaciones que exponen videos y noticias sesgadas sobre un acontecimiento. La perspectiva superior del ciberespacio es en realidad una temporalidad artificial creada mediante la interacción virtual de los usuarios de internet, que parten de la idea de que se puede reconstruir de forma exacta un acontecimiento a partir de la acumulación de las múltiples perspectivas que se pueden tomar de él; si esta forma de proceder resulta no plausible de derecho, cuando se lleva al hecho las consecuencias suelen ser problemáticas, porque la pluralidad de puntos de vista se conecta con la pluralidad de opiniones de los usuarios, con lo cual las interacciones virtuales hacen más difícil la acción de los directamente implicados en ese acontecimiento, puesto que tienen que tener en cuenta la censura moral que los participantes de internet puedan ejercer. El segundo tema tiene que ver con la forma en la que en el internet se conjugan las diferentes perspectivas, ya que ellas al ser mediaciones, no responden a una fusión de temporalidades entre dos individuos que se influencia recíprocamente creando un cambio cualitativo; en cambio la interacción de los usuarios de internet está determinada por una lógica causal en la que ellos ni siquiera se dan un tiempo para la reflexión, porque lo que les importa más es reaccionar ante un acontecimiento y no pensarlo; ya que el conjunto de imágenes compartidas por internet hará que otra noticia o fenómeno adquiera más importancia que el que en este momento está en boga.

Por esto nosotros creemos que la imagen del mundo interconectado creada por el internet esconde las consecuencias negativas que su uso conlleva, Bauman hace énfasis en esto cuando dice:

El mundo en el que viven los otros, los habitantes de los niveles 'inferiores' de la ciudad, es la antítesis del primero. Su característica principal es que se encuentra aislado de la red mundial de comunicaciones a la que están conectadas, y con la que sintonizan sus vidas, las personas del 'nivel superior' (Bauman, 2008 [2007]: 108-109).

Como podemos observar, una de las consecuencias negativas del uso del internet es que crea la imagen un mundo en la que la existencia depende de la interacción que se tiene con esa red de información, por ese motivo, todos aquellos que no tienen la posibilidad de conectarse y hacer de su vida un dato 
público que puede ser percibido y compartido, se quedan excluidos de ese mundo. Los dos temas que hemos tocado nos conducen a decir que el internet pertenece a un conjunto de determinaciones técnicas diferentes al cine, por ese motivo sus funciones no son las de expresar la realidad del cambio y la del todo abierto de la duración bergsoniana, sino las de un medio por el cual un conjunto de personas accede a un tiempo y espacio artificiales determinados por posibilidades económicas. Así la libertad virtual depende de la libertad económica, y la posibilidad de pensar está presa de una lógica que busca que las personas reaccionen y no reflexionen en la complejidad de las situaciones que les son presentadas; lo que en últimas consecuencias promueve que el ser humano haga uso de la inteligencia y su tendencia cuantificadora.

\section{CONCLUSIÓN}

Como conclusión diremos que el esfuerzo intelectual que animó este trabajo nos condujo a recorrer el camino de pensamiento de Henri Bergson concerniente a la crítica que hace del uso de la inteligencia por parte de la conciencia, la idea principal que quisimos resaltar de este estudio es que el filósofo francés identifica que el ser humano procede de forma inteligente ante las cosas, debido a que al hacer esto obtiene la ventaja de negar el tiempo efectivo para crear la idea funcional de que por debajo de la duración existe un espacio homogéneo infinitamente divisible. Esta idea sirve como el medio de una representación del mundo en la que todas las interacciones de los objetos materiales y las acciones de los seres vivos pueden ser calculadas, cuando se deducen las leyes que determinan el desarrollo del orbe. Esta idea es práctica en el instante en que el hombre necesita determinar su acción posible sobre las cosas, pero tiene el problema de olvidarse de que no todas las interacciones pueden ser entendidas bajo una mirada cuantificadora; es por eso que nuestro autor hace énfasis en que, incluso en la ciencia de su tiempo había posturas alternativas que no partían de esa forma de tratamiento práctico, por esa razón la termodinámica fue uno de los ejemplos utilizados en La evolución creadora para demostrar que el tiempo cualitativo forma parte de los fenómenos que conforman al mundo. Esta revaloración de la temporalidad efectiva y creadora es compartida por Bergson y Prigogine, los cuales tienen el objetivo de demostrar que es necesario estudiar el tiempo cualitativo y su participación en la conformación de los entes; es por ese motivo que nosotros creemos que los trabajos de estos dos autores nos ayudan a poner de manifiesto que la imagen del mundo creada por la inteligencia obedece a la impronta de la inteligencia, más que a una posibilidad real de la conciencia. 


\section{REFERENCIAS BIBLIOGRÁFICAS}

BACHELARD, G. 2011: La formación del espíritu científico. México: Siglo XXI. BERGSON, H. 1973: Introducción a la metafísica. Buenos Aires: Siglo veinte. , 2012: La evolución creadora. Buenos Aires: Cactus. ,2007. Materia y memoria. Buenos Aires: Cactus.

BAUMAN, Z. 2008: Tiempos líquidos. Vivir en una época de incertidumbre. México: Tusquets.

CHEVALIER, J. 1968: Historia del pensamiento. Tomo IV. Madrid: Aguilar.

DELEUZE, G. 2010: La imagen-movimiento. Estudios sobre cine 1. Buenos Aires: Paidós

KANT, I. 2014: Crítica de la razón pura. Madrid: Gredos.

LE ROY, E. 1932: Bergson. Barcelona: Labor.

MARTIN, J. 2010: «La imagen-movimiento. Deleuze y la relación Beckett-Bergson». Areté Revista de Filosofía, núm. 1, pp. 51-68.

PRIGOGINE, I., y STENGERS, I. 1994: Entre el tiempo y la eternidad. Madrid: Alianza.

PRIGOGINE, I., y STENGERS, I. «Naturaleza y creatividad». En: PRIGOGINE, I. 2009. ¿Tan sólo una ilusión? Una exploración del caos al orden. Barcelona: Tusquets. pp. 67-98 (or. 1982)

SCHNEIDER, E., y SAGAN, D. 2009: La termodinámica de la vida. Barcelona: Tusquets.

YANKÉLÉVITCH, V. 2006: Henri Bergson. México: Universidad Veracruzana.

RoBerto Alonso Hernández es es doctorando del programa de doctorado de Filosofía Contemporánea de la Benemérita Universidad Autónoma de Puebla.

Líneas de Investigación:

Ontología y metafísica

Correo electrónico: robertrussel22@gmail.com 